\title{
Indigenous Peoples Mandatory Representation in the Local Legislative Councils: Status, Challenges and Trajectories
}

\author{
Paquito M. Villanueva, Vilma B. Ramos, Larcy V. Villaroman, Aileen A. Villanueva \\ Nueva Ecija University of Science and Technology, Cabanatuan City, Philippines \\ Email: aileen_villanueva1973@yahoo.com
}

How to cite this paper: Villanueva, P.M., Ramos, V.B., Villaroman, L.V. and Villanueva, A.A. (2017) Indigenous Peoples Mandatory Representation in the Local Legislative Councils: Status, Challenges and Trajectories. Open Access Library Journal, 4: e4168.

https://doi.org/10.4236/oalib.1104168

Received: November 19, 2017

Accepted: December 18, 2017

Published: December 21, 2017

Copyright ( 2017 by authors and Open Access Library Inc.

This work is licensed under the Creative Commons Attribution International License (CC BY 4.0).

http://creativecommons.org/licenses/by/4.0/

\section{c) (i) Open Access}

\begin{abstract}
This paper gives an overview of the Mandatory Representation of the Indigenous People of the Philippines. At present, the indigenous peoples and other minority groups are under-represented in the country's local legislature. This paper gives rise to the rights of indigenous peoples' mandatory representation in all local government sanggunians at all levels and that IPMR shall be selected in accordance with the guidelines adopted and promulgated by themselves. The Mandatory Representatives represent the general concerns and welfare of all the ICCs/IPs. The study used descriptive research method and seeks to determine the status of the IPMR to describe the status of social, economic, cultural and political development initiated by them, it also seeks to identify challenges related to IPMR's political isolation, economic marginalization and socio-cultural orientation hindering effectiveness of their performance and also to determine future trajectories of the Indigenous Peoples Mandatory Representation. The study was derived from the IPMR of a patriarchal tribe known as Dumagat from Gabaldon, Nueva Ecija and the IPMR OF Palayan City composed of the tribes: Aeta, Applay, Bago, Kankanaey, Kalanguya, Dumagat and Ibaloi. The study found out that IPMRs are facing several challenges that hamper their performance and the study showed the need to LGUs to strictly comply with the mandate of RA 8371 recognizing the rights of Indigenous Peoples Mandatory Representative.
\end{abstract}

\section{Subject Areas}

Politics

\section{Keywords}

Indigenous People Mandatory Representative, Indigenous Cultural Communities, RA 8371 


\section{Introduction}

\subsection{Indigenous People's Mandatory Representation}

The recognition and protection of indigenous peoples' rights are one struggle that have been carried out passionately for many years now. The Indigenous Peoples' Rights Act (IPRA), or Republic Act 8371, is considered a landmark law. It is a comprehensive piece of legislation that includes not only the rights of indigenous peoples over their ancestral domain but also their rights to social justice and human rights, self-governance, and empowerment as well as cultural integrity [1]. Indigenous Cultural Communities/Indigenous Peoples (ICC/IPs) are a group of people or homogenous societies identified by others, who have continuously lived as organized community on communally bounded and defined territory, and who have under claims of ownership since time immemorial, occupied, possessed and utilized such territories, sharing common bonds of language, customs, traditions and other distinctive cultural inroads of colonization, non-indigenous, religions and cultures became historically differentiated from the majority of Filipinos. ICCs/IPs include peoples who are regarded as indigenous on account of their descent from the populations which inhabited the country, at the time of conquest or colonization, or at the time of inroads of non-indigenous religions and cultures, or the establishment of the present state boundaries, who retain some or all their own social, economic, cultural and political institutions, but who may have been displaced from their traditional domains [2].

The Indigenous Peoples represent nearly $14 \%$ of the country's population. They are among the poorest and the most disadvantaged social group in the Philippines. Illiteracy, unemployment and incidence of poverty are much higher among them than the rest of the population. IP settlements are remote, without access to basic services, and are characterized by a high incidence of morbidity, mortality and malnutrition [3].

Section 10, Article II of the 1987 Philippine Constitution provides that the State shall promote social justice in all phases of national development. Section 17, Article XIV of the 1987 Philippine Constitution also provides that the State shall recognize, respect, and protect the rights of indigenous cultural communities to preserve and develop their cultures, traditions, and institutions. It shall consider these rights in the formulation of national plans and policies [4]. To carry out this policy of the State, Sec. 16 of RA 8371 specifically provides that, IPs shall have the right to participate fully, if they so choose, at all levels of decision-making in matters which may affect their rights, lives and destinies through procedures determined by them as well as to maintain and develop their own indigenous political structures [5]. Consequently, the State shall ensure that the ICCs/IPs shall be given mandatory representation in policy-making bodies and other local legislative councils. These inherent rights of ICCs/IPs shall be provided mandatory representation in all policymaking bodies and in local legislative councils. ICCs/IPs representation shall be proportionate to their population, and shall have the same privileges as the regular members of the legislative bo- 
dies and/or policy making bodies [6].

In Nueva Ecija, particularly the towns of Gabaldon and Palayan City as the focus area of this study, with the considerable population of IP's in the locality they had already filled up their respective IPMR's since 2013, bestowed with regular membership in the Sanggunian Bayan concerned in concurrence with DILG Memorandum Circular No. 2010-119, NCIP Administrative Order No. 001, Series of 2009 and the provisions of RA 8371 [7].

This study is a starting point for further research and does not claim to be an exhaustive study of Indigenous participation in Local Legislative Council considering the constraints in time and resources for the project. It treats the tribes of Dumagat in Gabaldon, Nueva Ecijaand theBago tribe, Aeta, Kankanaey, Aplan and Ibaloi in the City of Palayan.

\subsection{Objectives of the Paper}

This paper has the general objective of evaluating the impact of Indigenous People's Mandatory Representation to the Local Legislative Council pursuant to the Indigenous Peoples' Rights Act (IPRA) otherwise known as RA 8371 which specifically provides that, ICCs/IPs have the right to participate fully, if they so choose, at all levels of decision-making in matters which may affect their rights, lives and destinies through procedures determined by them as well as to maintain and develop their own indigenous political structures. Consequently, the State shall ensure that the ICCs/IPs shall be given mandatory representation in policy-making bodies and other local legislative councils.

Specifically, the study describes the following:

1) The status of the IPMR pursuant to Section 10, Article II of the $1987 \mathrm{Phi}-$ lippine Constitution and Section 16 of RA 8371;

2) Described the status of social, economic, cultural and political development initiated by the IPMR's;

3) Identify challenges related to IPMR's political isolation, economic marginalization (salary benefits) and socio-cultural orientation hindering effective performance;

4) Determine future trajectories of the Indigenous Peoples Mandatory Representation and provide recommendations on how IPMR's would relate and adopt to local structural and functional governance.

\section{Research Methodology}

\subsection{Study Locale}

The study locale is in Gabaldon, Nueva Ecija and Palayan City both of the province of Nueva Ecija situated in the heart of Central Luzon which is one of the main islands in the Philippines (Figure 1).

\subsection{Data Gathering Technique}

The study used the descriptive research method in this study. Considering the 


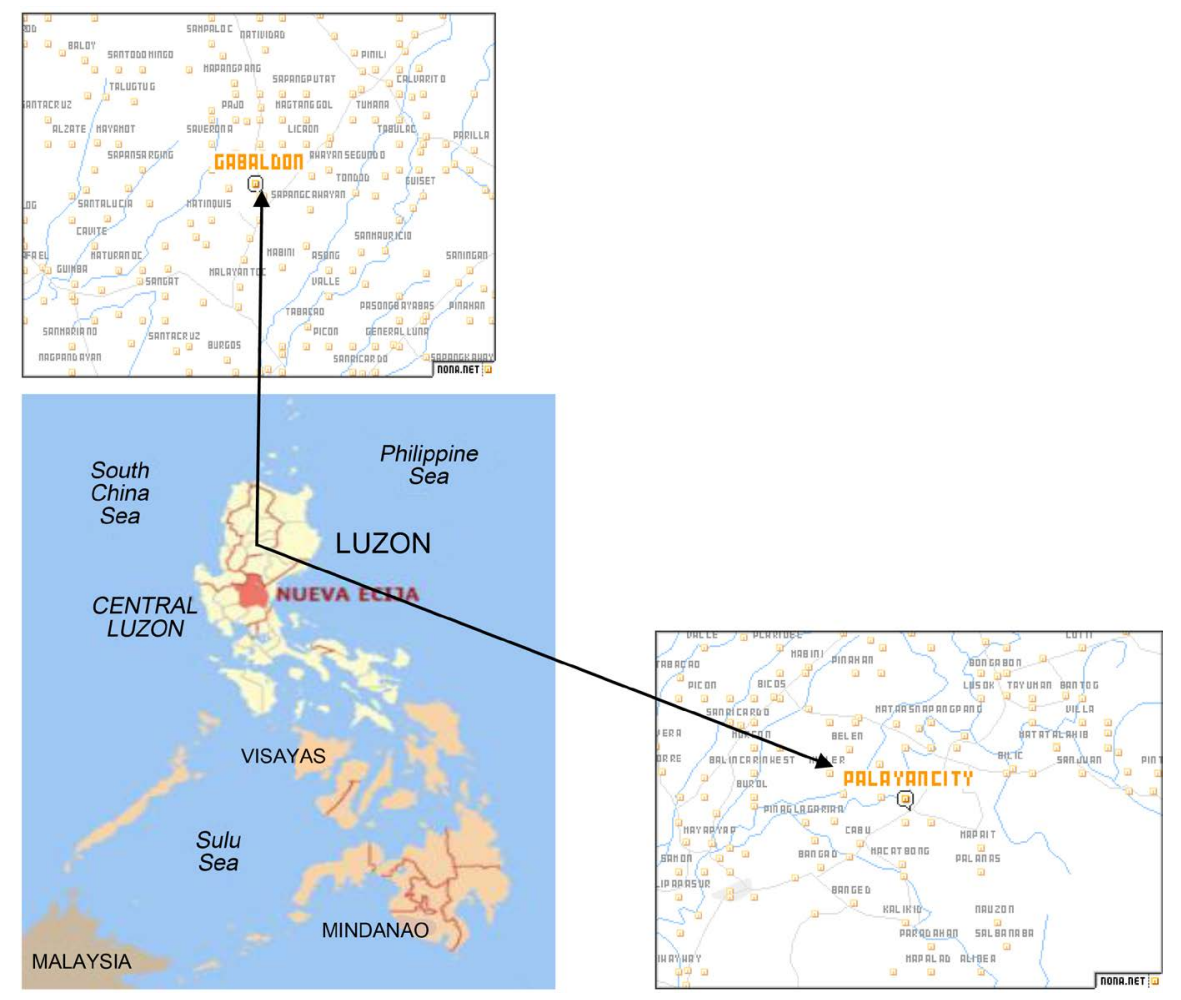

Figure 1. Location of Gabaldon, Nueva Ecija and Palayan City. Source: Google Maps. 2017.

respondents educational background and literacy levels, complex survey techniques were not used. Although IPRA was passed in 1997, the development of policies catering for indigenous education was considerably slow and inevitably captive, the herein respondents educational attainment is only an elementary level. Hence, data were collected through simple discussion, informal interview and observation. Descriptive Observation was used in studying and gathering information because when observing people you would often like to hear their own ideas about what they are doing and why and it could help you to understand the activity going on. Focus group discussion was also held attended by the IMPR in the concerned Sanggunian together with some regular Sanggunian members and representatives from NCIP. As a qualitative study, it inquires into the "why and how" IPMR's legislative contribution affects the economic and social development of their respective ICC's in the study area and in addition to documentary analysis, Sanguniaan Resolutions and Ordinances filed with the offices of the local government of Gabaldon, Nueva Ecija and Palayan City were used to gather information on the initiatives of bringing the agenda of ICC's in the Local Legislative Council. Interview with the IPMR's (Focus Group Discussion) was undertaken using open ended and free-willing discussion. Results of interview are reinforced by actual verification of data from the office of Provincial NCIP Office and actual observations. The qualitative-descriptive approach is used in the study as it may provide insights on the levels of decision-making which 
may serve as inputs to Local Chief Executives to implement non-discriminatory governance.

\subsection{Respondents}

The respondent-Indigenous Mandatory Representatives educational attainment for the City of Palayan and Gabaldon, Nueva Ecija is only an elementary level. Although IPRA was passed in 1997, the development of policies catering for indigenous education was considerably slow and inevitably captive. ICCs/IPs are very reluctant to go to school due to discrimination.

\subsection{Limitation of the Research}

In spite of best of efforts to minimize all limitations that might creep in course of the research, there were certain constraints within which the research was completed. Lack of available and/or reliable information because IPMRs in Palayan City and Gabaldon, in the province of Nueva Ecija still has a limited access in the local body politics, it remains that they have very limited and un-implemented sponsored resolutions. Record also shows that IPMR do not keep records such as activity reports and their accomplishment reports.

\subsection{Theoretical Framework/Legal Framework}

The theoretical framework for the study is established on the argument that Indigenous Peoples Mandatory Representation in the Local Legislative Councils has direct and indirect benefits to the community. It is based on the assumption that this mandatory representation of IPs in the Local Legislative Council is a manifestation of recognizing and promoting the rights of ICCs/IPs within the framework of national unity and development [8]. The connection between the ICCs/IPs and the IPMR is direct. It further argued that the implementation of Republic Act No. 8371, an Act to recognize, protect and promote the rights of Indigenous cultural communities/Indigenous Peoples may be analyzed using as parameter the performance of IPMRs in the local legislative council, on the deliverance of their role as regular member of particular legislative body. Approved and implemented Resolutions and Ordinances sponsored by concerned IPMRs could provide enough insights on the present and future ICCs/IPs economic, social and cultural well-being.

The legal framework for the Indigenous Peoples Representation in the Local Legislative Councils is well in placed. The IPRA Law echoes the "progressive" provisions of the 1987 Philippine Constitution. Section 17, Article IV of the 1987 Philippine Constitution provides that the State shall recognize, respect, and protect the rights of indigenous cultural communities to preserve and develop their cultures, traditions, and institutions. It shall consider these rights in the formulation of national plans and policies. To carry out this policy of the State, Sec. 16 of RA 8371 specifically provides that, IPs shall have the right to participate fully, if they so choose, at all levels of decision-making in matters which may affect 
their rights, lives and destinies through procedures determined by them as well as to maintain and develop their own indigenous political structures [9]. These state declarations engulf the correlative duty of the State to ensure that the ICCs/IPs shall be given mandatory representation in policy-making bodies and other local legislative councils. Such inherent right of ICCs/IPs to self-governance and self-determination includes the right to pursue their economic, social, and cultural development; promote and protect the integrity of their values, practices and institutions; determine, use and control their own organizational and community leadership systems, institutions, relationships, patterns and processes for decision making and participation. Finally to put into effect the constitutional provisions, DILG Memorandum Circular No. 2010-119, NCIP Administrative Order No. 001, Series of 2009 and the provisions of RA 8371 and Section 6 Part I Rule IV NCIP AO No. 1 Series of 1998 or the Implementing Rules and Regulation of RA 8371 provides that the ICCs/IPs shall be provided Mandatory Representation in Policy Making Bodies [10].

The IPMRs legislative contributions to their respective cultural communities are to improve their economic marginalization depending on how their IPMR will discharge his functional governance as regular member of the Local Legislative Council.

It is worthy to note that the ICCs/IPs are provided with mandatory representation in all policy making bodies and in local legislative councils and have the same privileges as the regular members of the legislative bodies and/or policy making bodies. The ancestral domains of the ICCs/IPs are the foundation of their right to self-determination. As such it is inherent to ICCs/IPs the right to decide their own priorities for development affecting their lives, beliefs, institutions, spiritual well-being and the lands they own, occupy and use. Towards these ends, The Constitution stresses out ICCs/IPs the empowerment ICCs/IPs to pursue and protect their legitimate and collective interests and aspirations in the formulation, implementation and evaluation of plans, policies and programs for national, regional and local development which may affect them [11].

According to Department of Interior and Local Government (DILG), RA 8371 as Legal Basis, it is not required for the adoption of the concerned local sanggunian of a resolution recognizing and or accepting the IPMR as ex-officio member, might as well the prior acceptance of the Local Chief Executive is not also required because it would only render nugatory the power of ICCs/IPs to select their own representatives according to their duly adopted local guidelines and traditions. It could never have been the intention of RA 8371 to give wide latitude of powers to the local sanggunian or the local chief executive to withhold their approval on selected ICC/IP representative thereby holding the decision of ICcs/IPs hostage to their sole discretion.

\subsection{Conceptual Framework}

From the afore-cited theoretical and legal framework the following conceptual framework guided the data gathering for the study (Figure 2): 


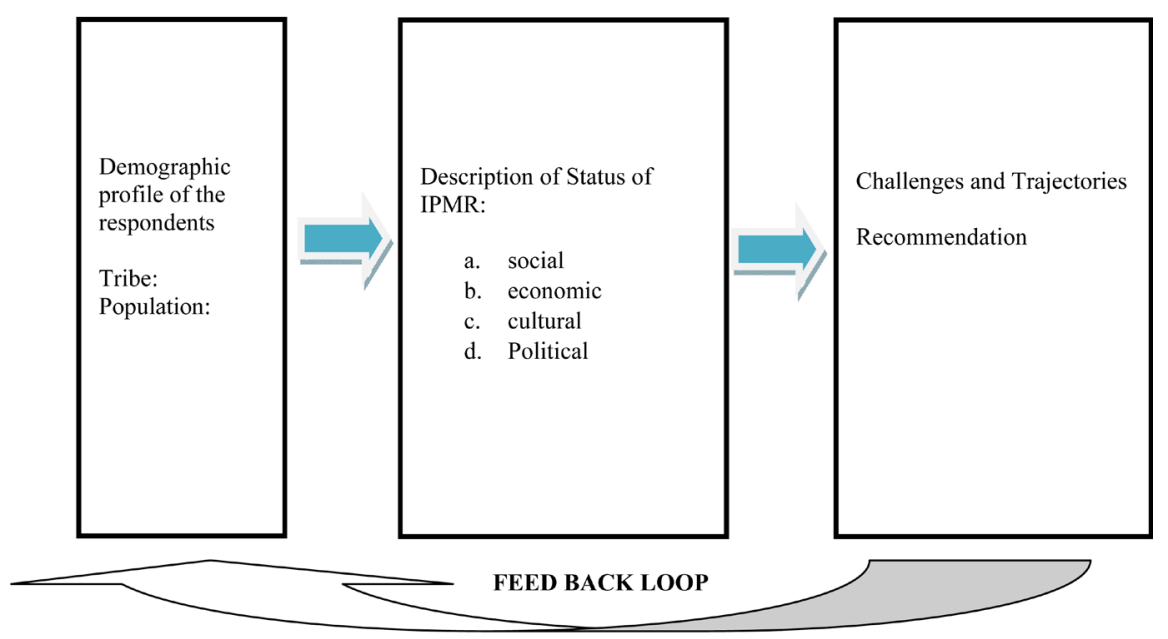

Figure 2. Research paradigm.

\section{Results and Discussion}

\subsection{Demographic Profile}

\section{Tribe and Population}

Table 1 presents the Demographic profile of Indigenous Communities of $\mathrm{Pa}$ layan City particularly their Population and specific tribes as of the first quarter of 2017. Palayan City as the Capital of Nueva Ecija is not wholly an Indigenous Cultural Community (ICC) because only a small portion of the total number of its inhabitants are indigenous people and less than of its $20 \%$ land area is composed of ancestral domains and there are only 2 known ICC's in the city, one is Brgy. Doña Josefa and Brgy. Langka covering 2100.30 hectares as their ancestral domain and as of Sept. 2016 the total number of IP's dwelling per barangay records is more or less 3078 composed of the tribes: Aeta, Applay, Bago, Kankanaey, Kalanguya, Dumagat and Ibaloi. There were some families of IP in the Poblacion area and these residing outside of the ICC's are the educated and more affluent IP's compared to those within the ICC's [12].

Table 2 also presents the Demographic profile of Indigenous Communities of Gabaldon, Nueva Ecija particularly their Population and specific tribes as of the first quarter of 2017. The municipality of Gabaldon lies in the foothills of the Sierra Madre Mountains in the southeastern part of the province. Topographically, Gabaldon consists of a strip of low-lands (the Gabaldon valley) and extensive upland areas in the Sierra Madre Mountains, covering two thirds of the total land area of the municipality. There were 6 areas covered in this municipality with ICCs/IPs. These were: settlement area in Brgy. Malinao, Brgy. Bugnan, Brgy. Calabasa, Brgy. Ligaya, SitioDupinga and Barangay Pinamalisan with an approximate population or 1233 as of the first quarter of 2017 [12].

Determination of the minimum threshold of ICCs/IPs population in a Local Government Unit to allow a mandatory representation in the local legislative council is that the total population of an LGU shall be divided by the number of sanggunian members as prescribed in the local government code and the result 
Table 1. Palayan city ICCs/IPs.

\begin{tabular}{ccccc}
\hline City/Municipality & Families & Individuals & Tribes & Chieftain Leader \\
\hline Palayan City & & & & \\
Brgy. Doña Josefa Proper & 73 & 274 & Bago & Lito Generoso \\
SitioBacao & 64 & 247 & Ayta & Carling Baclay \\
Brgy. Caballero & 45 & 79 & Bago & \\
SitioPinaltakan & 13 & 58 & Ayta & CelingLontavo \\
Brgy. Singalat & 19 & 87 & Kalanguya & \\
Brgy. Atate (Bliss) & 19 & 105 & Kankana-ey & \\
Brgy. Langka Proper & 296 & 1349 & Bago, Kanakana-ey & \\
Sitio Amaya & 19 & 135 & Dumagat & Ricardo Esmael \\
Sandeline & 183 & 708 & Bago, Applay, Ibaloi & \\
Brgy. Aulo & 9 & 36 & Bago, Kanakana-ey & \\
& 740 & 3078 & $\begin{array}{c}\text { Source: NCIP Nueva } \\
\text { Ecija Provincial Office }\end{array}$ & \\
\hline
\end{tabular}

Table 2. Gabaldon, NE ICCs/IPs.

\begin{tabular}{ccccc}
\hline City/Municipality & Families & Individuals & Tribes & Chietain Leader \\
\hline Gabaldon, N.E. & & & & \\
SitioPindangan, Brgy. Bugnan & 84 & 250 & Dumagat & Uliman Guitar \\
sitioCaanawan, Brgy. Calabasa & 19 & 108 & Dumagat & \\
SitioMabaldog, Brgy. Ligaya & 36 & 154 & Dumagat & Willy Dela Cruz \\
SitioDupinga, Brgy. Malinao & 43 & 157 & Dumagat & Renato Casamis \\
$\begin{array}{c}\text { SitioPag-asa, Brgy. Malinao } \\
\text { SitioPagsanghan, Brgy. }\end{array}$ & 42 & 164 & Dumagat & Bernard Casamis \\
Pinamalisan & 71 & 400 & Dumagat & Rodolfo Bendivil \\
& 295 & $\mathbf{1 2 3 3}$ & $\begin{array}{c}\text { Source: NCIP Nueva } \\
\text { Ecija Provincial Office }\end{array}$ & \\
\hline
\end{tabular}

or quotient thereof will serve as the minimum number to be met by an ICCs/IPs or in the event that it does not meet the ICCs/IPs land area shall be computed at $5 \%$ of the total land area of the LGU [13].

\subsection{Status of Indigenous People Mandatory Representative}

\subsubsection{Social and Economic Development Agenda Initiated by IPMRs}

The educational attainment of ICCs/IPs often lags behind that of other segments of the population. Access to and benefit from education for IPs is very limited, formal education is one that the IPMRs seen to be prioritize totally eliminating discrimination and they also believe that IPs should not only teach about the outside world, but should also support and value traditional knowledge, culture, livelihoods, world views and pedagogical methods. To do this appropriately, infrastructure, curricula and pedagogical materials should be tailored to the 
unique needs of indigenous learners, communities and peoples. This may include modified schedules, distance learning initiatives, mobile schools and Mother language instruction is recommended by them and that accordingly curricula and materials should also be intercultural, and should include accurate information about indigenous peoples, their cultures, their histories and lived experience. Negative and discriminatory stereotypes should also be removed from the curricula and materials of all schools and educational institutions [14].

Another focus of the IPMRs legislative Social and Economic Development Agenda is to secure their ancestral domain as it is vital for their income and socio-economic status. In the past, some tribal areas in Palayan City and Gabaldon, Nueva Ecija were redistributed to outsiders through titles, permits and licenses. As a result of discriminatory policies and practices, IP communities were constrained to ever decreasing ancestral domains. IP families have to eke out a living with high rates of unemployment, underemployment and widespread poverty. Limitation to self-employment amounts to discrimination, not only from the IP perspective, but also under Philippine and international law. Lack of security of tenure over land and natural resources results in limited opportunities for self-employment and income, and impairs individual and collective self-reliance. The absence of basic social services, in the area of health for instance, compounds the problem as disease persists in these IP communities. IPMR wants to facilitate full delineation and demarcation of Ancestral Domains of indigenous peoples through the issuance of Certificates of Ancestral Domain Title (CADT). Unfortunately, ancestral domain titling remains a burdensome process that has not undergone any review to simplify and streamline the process. An additional process put in place by Joint DAR-DENR-LRA-NCIP Administrative Order No. 01-12 (JAO 01-12), issued in 2012 with the objective to address jurisdictional and operational issues between and among these land titling agencies, has resulted in undue delay in the issuance and registration of CADTs [15].

Effective mobilization of human and natural resources is crucial to socioeconomic development. IPMRs want to end the IPs and non-IPs discriminatory issues. IPMRs believe that this will lead to efficiencies at the level of the individual, the community and ultimately, the economy of ICCs/IPs. Public and private initiatives for the socioeconomic development and nondiscrimination of ICCs/IPs have to take place in the wider framework of policies embodied in IPRA and the government's development plans. IPMRs would like to legislate ordinance in the local legislative council to provide educational assistance to poor but deserving IPs and to provide health services to the ICCs/IPs. They would to enhance skills among IPs for work productivity and self-employment particularly through traditional livelihood programs. However at this point of time, this Social and Economic Development Agenda of IPMRs remains to be realize because of the lack of support from the Local Chief Executive which appropriation of budget to an approved resolution of IPMRs is less prioritize by the Sanggunian allegedly due budgetary constraints. IPMRs wants to be part of the Technical working 
Group in formulation of their own development plans and allow them to participate and formulate their own development and land use plans in concurrence of the Sanggunian. IPMR of Gabaldon, Nueva Ecija and Palayan City aims to strengthen and support indigenous peoples' traditional occupations, arts and crafts, and livelihoods and ensure that sustainable and community-based economic and livelihood programs are jointly developed and implemented with indigenous peoples. Likewise, the IPMR would like to provide sufficient and culturally responsive educational institutions in their community and undertake the implementation of indigenization and mother-tongue programs of the Department of Education, jointly with indigenous peoples and experts. IPMR of Gabaldon, Nueva Ecija would like also to encourage the participation of the elders in institutions of education and the integration of indigenous knowledge systems to reinforce the positive cultures and values and teach these especially to the youth. One of the programs of the IPMR of this two municipality is to address the right to health of indigenous peoples by way of Modified Conditional Cash Transfer (MCCT) program of the Department of Social Work and Development (DSWD). This modified program is meant to address the main problems identified with the Conditional Cash Transfer Program (CCT) or Pantawid Pamilyang Pilipino Program (4Ps) [16].

Table 3 presents the numbers of ordinances and resolutions accomplished by the incumbent IPMRs of Palayan City and Gabaldon, Nueva Ecija since 2013. Records show that IPMRs are not functioning well in the performance of their duty as a regular member of the local legislative council.

Table 3. IPMRs legislative accomplishment.

\begin{tabular}{|c|c|c|c|c|}
\hline Palayan City & $\begin{array}{c}\text { Source: Office of the Secretary of } \\
\text { SanggunianPanglunsod }\end{array}$ & & & \\
\hline $\begin{array}{l}\text { Legislative } \\
\text { Year }\end{array}$ & sponsored ordinances & $\begin{array}{l}\text { Sponsored } \\
\text { resolutions }\end{array}$ & $\begin{array}{l}\text { Approved } \\
\text { ordinances }\end{array}$ & $\begin{array}{l}\text { Approved } \\
\text { Resolutions }\end{array}$ \\
\hline 2013 & 0 & 0 & 0 & 0 \\
\hline 2014 & 0 & 0 & 0 & 0 \\
\hline 2015 & 0 & 0 & 0 & 0 \\
\hline 2016 & 0 & 0 & 0 & 0 \\
\hline 2017 & 0 & 0 & 0 & 0 \\
\hline $\begin{array}{l}\text { Gabaldon, } \\
\text { N.E. }\end{array}$ & $\begin{array}{c}\text { Source: Office of the Secretary of } \\
\text { Sanggunian Bayan }\end{array}$ & & & \\
\hline $\begin{array}{l}\text { Legislative } \\
\text { Year }\end{array}$ & Sponsored ordinances & $\begin{array}{l}\text { Sponsored } \\
\text { resolutions }\end{array}$ & $\begin{array}{l}\text { Approved } \\
\text { Ordinances }\end{array}$ & $\begin{array}{l}\text { Approved } \\
\text { Resolutions }\end{array}$ \\
\hline 2013 & 0 & 0 & 0 & 0 \\
\hline 2014 & 0 & 0 & 0 & 0 \\
\hline 2015 & 0 & 3 & 0 & 3 \\
\hline 2016 & 0 & 0 & 0 & 0 \\
\hline 2017 & 0 & 0 & 0 & 0 \\
\hline
\end{tabular}




\subsubsection{Cultural}

While there are several government cultural programs and policies, IPMR programs for promoting indigenous peoples' culture through festivals are constrained because it does not fall under their legislative control which most of the time due to this it misrepresents their traditional cultural expressions. There is demand from indigenous peoples for increased and sustained support for Schools of Living Traditions (SLTs), a program of the National Commission on Culture and the Arts (NCCA). The IPMRs recommend for the adoption of implementing rules for Article 31 of the IPRA on Community Intellectual Rights for the protection of indigenous peoples' knowledge systems and practices (IKSPs) and intangible cultural heritage. IPMRs adheres to maintain the cultural integrity within the ancestral domains, the holistic and integrated adherence of indigenous peoples to their respective customs, beliefs, traditions, indigenous knowledge systems and practices, and the assertion of their character and identity as peoples remains inviolable. The IPMRs maintains the quality of being compatible and appropriate to the culture, beliefs, customs and traditions, indigenous systems and practices of ICCs/IPs [17].

\subsubsection{Political}

The selection process is started by crafting, presentation and ratification of a local guideline by the elders/leaders of the concerned ICCs/IPs. The local guidelines define among others the qualification, disqualification, and the selection process based on the customary practices of ICCs/IPs. The National Commission on Indigenous Peoples (NCIP) is tasked to validate and document the selection process with the assistance of the Department of Interior and Local Government (DILG) [18].

The City of Palayan and Municipality of Gabaldon, Nueva Ecija is home to the indigenous people known as Dumagat, Bago, Kankana-ey, Applay, Ibaloi and Ayta living peacefully in their jurisdiction. They are duly organized under the supervision of their Council of Elders who are regarded with a certain degree of wisdom, integrity, esteem and dignity and who are generally relied upon by the community members as leaders in the pursuit of community concerns. They lead and assist the community in decision-making processes aimed at protecting and promoting the sustainable development of their ancestral domains [19].

Political participation through representation is a crucial, though it is not the sole indicator of how well indigenous peoples are integrated in governance. An IPMR should know how to advocate the interest and well-being of the Indigenous Cultural Communities/Indigenous Peoples and present an agenda in the local legislative body to address concerns. IPMR should also be well-informed on the IPRA and other related issuance. IPMR will not only represent and consult his/her ethnolinguistic group but all the other indigenous peoples in the municipality [20].

The Indigenous groups of this study had a very high standard for leadership. Leaders usually is knowledgeable about customs and tradition, have certain spe- 
cialized knowledge, articulate, generous, brave and physically strong. Furthermore leader must be of personal integrity, reliability, honesty, wisdom and with a sense of justice.

Section 9, of the National commission on Indigenous Peoples (NCIP) Administrative Order No. 1 series of 2009 provides that the minimum requirements for one to qualify as ICCs/IPs representative in the local legislative councils are that:

1) The IP representative must be a natural born Filipino citizen;

2) He/She must be a registered voter in the barangay, municipality, city, province, or Baranggay where he/she intends to assume office;

3) He/She must be a bona fide IP by blood or consanguinity, an acknowledged leader of the ICCs/IPs of which he/she is a member, and has continuously engaged in ICCs/IPs undertakings setting up a track record of services for ICCs/IPs in a given LGU as certified by the NCIP;

4) $\mathrm{He} / \mathrm{She}$ must be able to read and write; and,

5) $\mathrm{He} / \mathrm{She}$ must be knowledgeable of and practices the customary ways of ICCs/IPs of which he/she is a member.

IPMR is chosen by their own community in accordance with a process to be determined also by them in close coordination with the NCIP and DILG to come up with a measure ensuring the full participation of ICCs/IPs in matters affecting their development. The Mandatory Representatives shall represent the general concerns and welfare of all the ICCs/IPs [18]. The powers, duties and function of IPMR is also the same as that of the regular members of local legislative councils as provided for in the Local Government Code of 1991, otherwise known as RA 7160 [21].

The term of office of IPMRs in the local legislative council is for a period of three (3) years from the date of assumption of office and can be re-endorsed for another term but in no case shall serve for more than three (3) consecutive term [22].

\subsubsection{Determining Challenges and Trajectories of the IPMR}

Challenges related to IPMR's political isolation, economic marginalization (salary benefits) and socio-cultural orientation hindering effective performance.

Corollary IPMR have the right pursuant to Section 16 of A 8371 to participate fully in all levels of decision making in all policy making bodies and local legislative council, however IPMR are facing several issues and concern that affects their performance. Despite the mandate of Section 16 of RA 8371 to all local government units to fully recognize the IPMR to become member of their sanggunian in their territorial jurisdiction, they were met with less enthusiasm and the difficulty of local chief executive to appoint $M$ who are not sympathetic to his political interest.

The following are the common issues and concerns that IPMRs are combating:

1) Is there a need to for the Local Chief Executive to accept the duly selected Mandatory Indigenous Peoples Representative before they assume office as 
member of the legislative council;

2) Is it within the prescribe power of the Local Chief Executive to appropriate funds for the approved resolutions of IPMR;

3) Is there a need for the Sanggunian concerned to pass or approved a resolution accepting and concurring the duly confirmed IPMR by the NCIP before assumption to office as member of the legislative council;

4) Is it within the power of the Sanggunian to resolve any question on the legitimacy of the selection of the ICCs/IPs confirmed IPMR by the NCIP and recognized by the DILG and that is there a need to pass and approved a resolution with regards to the salaries and benefits and other emoluments for IPMR;

5) Is it possible for the LGU to require more requirements aside from CERTIFICATE OF AFFIRMATION and Oath of Office;

6) The most controversial challenge is that, is there an appropriate trainings for IPMRs to know the provisions of IPRA Law, and other issuances vis-a vis the Local Government Code and other related laws addressing the rights and responsibilities of IPs.

The welfare and development of indigenous peoples must be addressed in a manner that is holistic-ranging from areas such as culture, health, economy, and education to peace and political participation. Fields and agendas regarding indigenous peoples' issues must be charted and led by indigenous peoples themselves. The challenge to provide political environment allow Indigenous Peoples to pursue their own agenda free from harm or discrimination. Ultimately, the building of such political environment and the provision of such services are dependent on the recognition and preservation of indigenous peoples' human rights [23]. Compensation, benefits and other emoluments of IPMR are regularly received by the IP representative the same with that of the regular members of the concerned legislative bodies as prescribed in RA 7160 [24].

\subsubsection{Trajectories}

Since Republic Act 8371 or the Indigenous Peoples' Rights Act (IPRA) was implemented two decades ago, it had opened greater opportunities for IPs and further empowered the community that used to label itself as marginalized. The advent of the IPRA Law has overshadowed speculations and unfounded doubts that the tribal peoples and communities in the Philippines are abandoned or neglected and that they are only meant to exist outside the periphery of development, much less a part of national life. IPs are randomly distributed all over the archipelago and are now exercising their rights under IPRA.

The heavy focus on empowerment and upland development is to transform ICCs/IPs into major players and partners in nation development. The government had allocated scarce resources for ancestral domain delineation and basic social services. The donor community, non-governmental organizations had pledged to extend financial aid for livelihood and community empowerment. IPs/ICCs, have started to assess local resources as their counterpart in holistic development initiatives, in several cases, in partnership with non-governmental 
institution and civil society. These trends signal that IPRA implementation would be a tremendous, long-term collective endeavor in the context of cultural integrity.

While the study showed that IPMRs in Palayan City and Gabaldon, in the province of Nueva Ecija still has a limited access in the local body politics, it can be said that they are already participating in the local legislative council, the inequality between them and the majority is no longer an issue. Increasingly, IP leaders are gaining headway in the political process, with some getting seats in the barangay council-and even in the municipal government as elected Sanggunian Member in the case of Palayan City-when they ran successfully in previous election.

Through trainings and seminars future IPMRs can easily facilitate dialogues between their communities and government officials. They can initiate consultations about issues affecting IP communities, and will be able to communicate directly or submit petitions to the government when needed. To promote their cultural traditions and strengthen indigenous governance systems, the IPMRS need a complete recognition from the LCE that would allow them to be more autonomous and lessen their dependence on political connections. With greater unity, they will be able to get better presentation in local councils that make decisions on issues affecting the lives of indigenous communities.

\subsection{Conclusions and Recommendations}

\subsubsection{Conclusions}

The study showed that the Indigenous Peoples Mandatory Representation in the Municipality of Gabaldon and Palayan City had no enough legislative accomplishment in bringing the agenda of their respective communities in their respective local councils since they assumed office in 2013. According on the findings, the Municipality of Gabaldon and Palayan City meets the minimum threshold of ICCs/IPs population in their respective Local Government Unit to allow them a mandatory representation in the local legislative council pursuant to Section 10, Article II of the 1987 Philippine Constitution and Section 16 of RA 8371. There are some constraints in terms of conflicting perspectives in political identity of IPMR; they were met with less enthusiasm and difficulty in gaining recognition from local chief executive to appoint especially those who are not sympathetic to the political interest of LCEs. Lack of funds on the part of traditional leaders forces them to rely on political connections to obtain support for the needs of their communities. They only had very limited sponsored resolutions but remain un-implemented because of lack of support from the Local Chief Executives and due to budgetary constraints. It was also noted during the actual interview that IPMRs are not sincere enough in performing their roles as local legislator but instead they are just attending the sessions just for the sake of attendance and compensation but never indeed raised the diversity of interests and needs of their community in the council. The journals of approved and or- 
dinances and adopted resolutions of the Sanggunian of subject municipalities manifested that IPMRs didn't actively participate in the decision-making of the Council and they failed to contribute to the strategic direction of the Council through the development.

On the challenges found in this study, the mandate of the IPRA Law of mandatory representation in the local legislative council either Sanggunian Panglungsod, Sanggunian Bayan and Sanggunian Panglalawigan and even in the Baranggay is within the mandate pursuant to Sec. 6 Rule IV of the Implementing Rules and Regulations (IRR) of RA 8371 clearly not covered by RA 7160 or the Local Government Code of 1991. It is mandated that ICCs/IPs shall be provided mandatory representation in all local government sanggunians at all level. Sec. $11,12,13$ and 16 of the Implementing Rules and Regulations (IRR) of RA 8371 also provides that IPMR shall be selected in accordance with the guidelines adopted and promulgated by themselves and on the basis only of Certificate of Affirmation issued by the NCIP, IPMRs then should immediately assume office without the need of resolution from sanggunian accepting and concurring their appointment.

Indigenous Peoples Mandatory Representation is only pursuant to the mandate of IPRA Law that the LGU must strictly comply with.

\subsubsection{Recommendations}

Based on the findings of this study, the researcher arrived to the following recommendations on how IPMR's would relate and adopt to local structural and functional governance.

1) For the government

a) The researcher recommend to the government to come out with legislation that IPMRs should be fully institutionalized with an adequate budget share from the Internal Revenue Allotment.

b) For the government to correct the enactment of the Joint Memorandum Circular of the DLG and NCIP on Mandatory representation of IPs in Local Legislative bodies of LGUs to compel all LGU to install all IPMR chosen by ICCs/IPs without the prior acceptance or approval of the LCE before the IPMR is allowed to assume office.

c) The national and local government in collaboration with the NCIP to implement regular training for duly-appointed IPMRs competence required to fully ventilate their concerns and sentiments during sanggunian sessions and enable them to share their best practices on how IPs exercise their rights within the context of IPRA Law;

d) The NCIP should coordinate with the Department of Education to come up with a Joint Resolution to ensure Indigenous Peoples' education to be given priority to help increase their literacy rate and eliminate bullying and discrimination of IP students.

e) For the government to revisit DAR-DENR-LRA-NCIP Administrative Order No. 01-12 (JAO 01-12) issued in 2012 because according to ICCs/IPs this 
administrative order resulted in undue delay in the issuance and registration of CADTs.

2) For the Municipality of Gabaldon and Palayan City

f) For the Local Chief Executives not to intervene or influence the selecting process of IPMRs because this is a clear violation of the inherent rights of ICCs/IPs to Self-governance and self-determination and respects the integrity of their values, practices and institutions. The state shall instead guarantee the rights of ICCs/IPs freely pursue their economic, social and cultural development.

g) All tribes at all levels should be included and consulted in determining sustainable development of ancestral domain for ICCs/IPs.

h) Concerned Local Sanggunian shall enact an ordinance providing the appropriation of funds for the adopted and promulgated resolutions related to Social and Economic Development Agenda of ICCs/IPs to avoid the unjustified failure or refusal by the Local chief Executive (LCE) to include an item in the Appropriations Ordinance.

i) For the concerned local sanggunian to formulate a development and land use plans, and allow IP communities to participate in planning and be part of the Technical working Group in formulation of their own development plans.

3) For the future researchers

The researcher recommends that future researchers on this field should use different model to study the impact of IPMRs legislative contribution and perhaps look into the challenges and issues of LGUs having difficulty in implementing the mandatory representation of IPs/ICCs in the local sanggunians.

\section{References}

[1] Coalition for Indigenous Peoples' Rights and Ancestral Domains (1998) Guide to RA 8371 IPRA of 1997 (Ilo/Bilance-Asia Department 1999). Coalition for Indigenous Peoples' Rights and Ancestral Domains, Manila, 3-4.

[2] National Commission on Indigenous Peoples (2013) Indigenous Peoples of the Philippines. http://ncipro67.com.ph/indigenous-peoples-of-the-philippines

[3] De Vera, D.E. (2012) IFAD Poverty Report 2012. Executive Director, PAFID. Presented at the RNIP Regional Assembly, Hanoi.

[4] Official Gazette of the Republic of the Philippines (1987) The 1987 Philippine Constitution. http://www.officialgazette.gov.ph/constitutions/1987-constitution/

[5] Arellano Law Foundation (1997), Republic Act No. 8371 Indigenous Peoples Rights Act. Philippine Laws and Jurisprudence Data Bank, 7. www.lawphil.net/statutes/repacts/ra1997/ra_8371_1997.html

[6] National Commission on Indigenous Peoples (NCIP) (1998) Administrative Order No. 1, Series of 1998, or the Implementing Rules and Regulations (IRR) of RA 8371. National Commission on Indigenous Peoples, Baguio City, 12.

[7] National Commission on Indigenous Peoples Office-Nueva Ecija Provincial Office (2015) Unpublished Activity Report 2015. Nueva Ecija, 46-48.

[8] Guan, J. and Ipra, R.b.G. (1999) Legalizing Dispossession? IBON Special Release 42.

[9] Congress of the Philippines (1997) Republic Act No. 8371 Indigenous Peoples Rights Act. Official Gazette of the Republic of the Philippines. 
http://www.lawphil.net/statutes/repacts/ra1997/ra_8371_1997.html

[10] Department of the Interior and Local Government (2011) National Commission on Indigenous Peoples Joint Circular No. 001 Series of 2011.

[11] DILG-Legal Opinions (2014) Department of the Interior and Local Government Legal Opinion on the Implementation and Evaluation of Plans, Policies and Programs for National, Regional and Local Development Which May Affect Indigenous Peoples. http://www.dilg.gov.ph/legal-opinions-archive/

[12] National Commission on Indigenous Peoples Office-Nueva Ecija Provincial Office (2013) Unpublished IPs Statistics Report 2013, Nueva Ecija.

[13] National Commission on Indigenous Peoples (NCIP) (1998) Section 6, Part I, Rule IV of the National Commission on Indigenous Peoples (NCIP) Administrative Order No. 1, Series of 1998, or the Implementing Rules and Regulations (IRR) of RA 8371.

[14] UN Committee on Economic, Social and Cultural Rights (UN CESCR) (1999) General Comment No. 13: the Right to Education (Art. 13 of the Covenant). http://www.refworld.org/docid/4538838c22.html

[15] National Commission on Indigenous Peoples Office-Nueva Ecija Provincial Office. Unpublished Accomplishment Report 2015. 54-55.

[16] National Commission on Indigenous Peoples Office, Nueva Ecija Provincial Office (2015) Unpublished Accomplishment Report. 60.

[17] National Commission on Indigenous Peoples Office, Nueva Ecija Provincial Office (2015) Unpublished Accomplishment Report. 70-71.

[18] National Commission on Indigenous Peoples (NCIP) (2009) Administrative Order No. 1, Series of 2009, National Guidelines for Mandatory Representation of Indigenous People in Local Legislative Councils.

[19] National Commission on Indigenous Peoples Office, Nueva Ecija Provincial Office (2015) Unpublished Activity Report. 110-114.

[20] Agabin, P.S. (2011) The Influence of Indeginous Law in the Development of New Concept of Social Justice. Integrated Bar of the Philippines Journal, 36, 1-18.

[21] Sec. 9, of the National Commission on Indigenous Peoples (NCIP) Administrative Order No. 1 Series of 2009.

[22] Congress of the Philippines (1991) Republic Act No. 7160. http://www.officialgazette.gov.ph/1991/10/10/republic-act-no-7160/

[23] DILG (2013) Unpublished Activity Report.

[24] Section 13, NCIP Administrative Order No. 001, s. 2009 National Guidelines for the Mandatory Representation of Indigenous Peoples in Local Legislative Councils. 